\title{
INFORMATIKA KESEHATAN MASYARAKAT DALAM BIDANG PENDIDIKAN
}

\author{
Muhamad Faisal Pataha *)
}

\section{Informatika Kesehatan}

Informatika (Informatics) "...the science and art of turning data into information" ilmu dan seni untuk mengubah data menjadi informasi (Hebda, 2009).

Informatika Kesehatan (Health Informatics) "...the application of computer and information science in all basic and applied biomedical sciences to facilitate the acquisition, processing, interpretation, optimal use, of communication of health related data" Aplikasi komputer dan ilmu informatika dalam ilmu biomedis dasar dan terapan untuk memfasilitasi akuisisi, pengolahan, penafsiran, penggunaan optimal, komunikasi yang terkait dengan data kesehatan (Hebda, 2009),

Informatika Kesehatan (Health Informatics) "...integrated effort to collect, process, report and use of health information and knowledge to influence policy making, program action and research" Upaya untuk mengumpulkan, memproses, laporan dan penggunaan informasi kesehatan dan pengetahuan yang mempengaruhi dalam pengambilan pembuatan kebijakan, pelaksanaan program dan penelitian terpadu. (WHO, 2003).

Dalam bidang kesehatan, informasi adalah hal yang sangat penting, karena semua hal mengenai pasien adalah informasi yang harus dikelola dengan baik dan aman, sehingga dibutuhkan suatu sistem yang aman dan berjalan lancar agar seluruh informasi itu dapat digunakan untuk kepentingan pengobatan pasien.

Namun, tidak semua pengelola dan praktisi sarana pelayanan kesehatan sadar akan pentingnya penggunaan teknologi informasi sehingga pelayanan terhadap pasien tidak dapat dilaksanakan dengan baik, pada akhirnya terjadinya peningkatan biaya \& berkurangnya pendapatan dari sarana pelayanan kesehatan akibat tidak efisiennya pelayanan yang diberikan pada pasien.

Rendahnya kualitas ketersediaan data, informasi dan pengetahuan sektor kesehatan suatu negara, mendesak dibentuknya suatu infrastruktur informasi kesehatan nasional. Konektivitas dan manajemen pengetahuan menjadi penting untuk meningkatkan status kesehatan dan sistem kesehatan yang lebih baik.

Informatika Kesehatan dapat menjadi solusi dalam bidang kesehatan diantaranya : 1). Peningkatan kualitas pengelolaan sarana dan pelayanan kesehatan, 2). Peningkatan keamanan dan keselamatan pasien dan 3). Penyebaran informasi dan pendidikan kesehatan.

\section{Informatika Kesehatan Masyarakat}

Konteks Informatika Kesehatan Masyarakat secara umum merupakan gabungan dari beragam bidang ilmu pengetahuan selain dari bidang kesehatan, salah satu bidang ilmu yang medukung dalam informatika kesehatan masyarakat adalah Ilmu Komputer dan Ilmu Informasi.

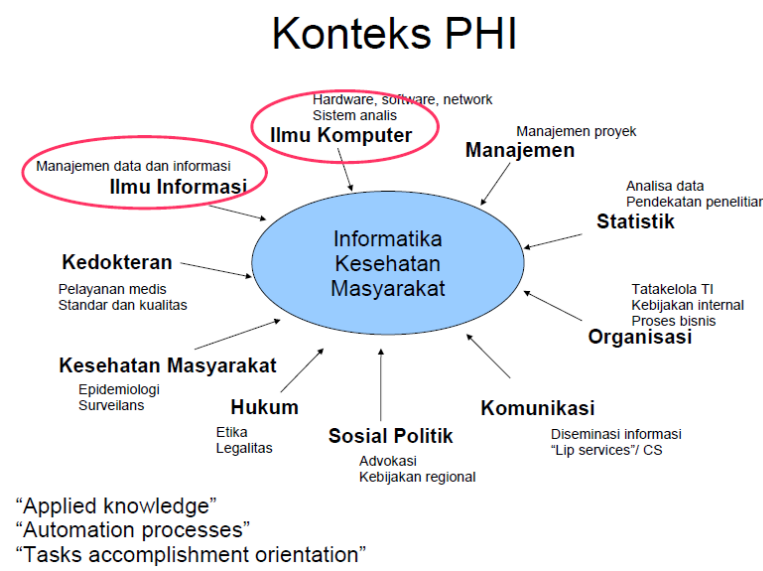

Penerapan Ilmu Komputer dan Ilmu Informasi secara sistematis dalam praktek, penelitian dan pembelajaran kesehatan masyarakat "...The systematic application of informationand computer science and technology to public health practice, research, and learning..." (Yassnoff \& Carroll, 2000).

Informatika Kesehatan Masyarakat (Public Health Informatic) dapat kita temukan secara luas diantaranya meningkatkan kesehatan dalam hal ini pasien secara individu dan mencegah adanya penyakit atau cidera pada komunitas yang tidak atau belum memiliki 
resiko, selain itu mengeksplorasi potensi intervensi pada suatu sebab penyakit dan siklus alamiah penyakit maupun kejadian, bahkan dapat merefleksikan program kesehatan yang telah direncanakan oleh pemerintah. Selain itu Informatika kesehatan masyarakat berfokus kepada populasi untuk mendukung pelayanan, pendidikan dan pembelajaran kesehatan masyarakat.

Perkembangan teknologi informasi dan komunikasi (Information and Communication Technologies) di beberapa negara maju memberikan pengalaman positif terhadap kesehatan, dengan teknologi informasi, dunia kesehatan mampu memberikan informasi dan pelatihan tingkat lanjut bagi dunia pendidikan (situs tenaga kerja kesehatan, pembelajaran jarak jauh), meningkatkan pelayanan kesehatan dan manajemen bencana (pemetaan bencana dan kerusakan infrastrukturnya dan pemanfaatan Personal Digital Assistant), dan meningkatkan pelayanan kesehatan publik melalui transparansi dan efisiensi (situs informasi kesehatan, konsultasi via email, tender kesehatan).

Perkembangan sistem informasi kesehatan di negara berkembang tersebut mengalami beberapa masalah mendasar diantaranya :

1. Infrastruktur fisik yang belum adekuat.

2. Akses mayoritas populasi terhadap teknologi kesehatan masih kurang.

3. Kurangnya kemampuan penggunaan teknologi kesehatan.

\section{Informatika Kesehatan Masyarakat Dalam Bidang Pendidikan}

Meningkatkan status kesehatan di suatu negara tentunya membutuhkan kerjasama bidang-bidang manajemen kesehatan personal (individu), pelayanan kesehatan (praktisi klinis), kesehatan masyarakat, dan penelitian yang terkait kesehatan. Salah satunya memberikan pendidikan bagi profesional kesehatan dalam penggunaan teknologi kesehatan dan menyediakan akses serta konektivitasnya diharapkan akan mampu mengurangi kesenjangan teknologi bidang kesehatan.

Sektor kesehatan merupakan bidang yang kaya informasi (information intensive domain). Sayangnya, bidang ini relatif tertinggal dalam menerapkan konsep, aplikasi maupun inovasi pengelolaan informasi untuk mewujudkan pelayanan, pendidikan dan penelitian kesehatan yang efektif, efisien dan bermutu tinggi. Dengan semakin ketatnya persaingan, pengelolaan informasi, pembelajaran dan pengetahuan.

Beberapa organisasi kesehatan di Indonesia menghadapi beberapa masalah seperti lemahnya surveilans, kegagalan pengembangan Sistem Informasi Kesehatan di beberapa daerah mapun di rumah sakit menunjukkan betapa mendesaknya kebutuhan terhadap tenaga ahli sistem dan manajemen informasi kesehatan. Tenaga ahli tersebut diharapkan tidak hanya mampu mendiagnosis masalah yang terkait dengan sistem dan manajemen informasi, namun juga mampu memberikan solusi dengan pendekatan sistem informasi.

Tujuan utama dalam menghasilkan tenaga profesional yang menguasai informatika kesehatan masyarakat yang memiliki pengetahuan dan ketrampilan dalam merancang dan merekayasa sistem informasi untuk peningkatan kinerja pelayanan kesehatan dan mengidentifikasi, memanfaatkan teknologi informasi dan komunikasi dalam merencanakan, mengimplementasikan dan mengevaluasi sistem maupun manajemen informasi kesehatan, dan memiliki wawasan yang komprehensif mengenai cakupan informatika kesehatan masyarakat.

Beberapa pusat pendidikan informatika kesehatan mungkin memiliki program tambahan tertentu seperti kunjungan ke lapangan/praktik kesehatan, kerja sama dengan pihak luar negeri, dan pendidikan jarak jauh melalui E-Learning. Baik yang berasal dari disiplin ilmu kesehatan masyarakat, kedokteran, farmasi, keperawatan, teknik, ekonomi, sosial, kolaborasi bidang informatika kesehatan, manajemen, dan teknologi informasi, serta tidak menutup keterlibatan bidang lainnya, kita harapkan dapat menjembatani terciptanya sistem informasi kesehatan yang lebih baik, sehingga diharapakan dapat berperan pada pengembangan dan implementasi suatu sistem informasi kesehatan, maupun bekerja sama dengan pihak/vendor/departemen teknologi informasi, dan berusaha memahami kebutuhan komunitas kesehatan dalam pemanfaatan teknologi informasi guna mewujudkan pelayanan kesehatan yang lebih baik. 


\section{DAFTAR PUSTAKA}

Fuad, 2009, "Informatika kesehatan masyarakat", Minat SIMKES Prodi S2 Ilmu Kesehatan Masyarakat Fakultas Kedokteran, Universitas Gadjah Mada, Yogyakarta, https://www.scribd.com/doc/14024720/Inform atika-Kesehatan-Masyarakat/.

Hebda, 2009, "Training puts nurses on the forefront of technological advances", Edisi ketiga, Rineka Cipta, Jakarta.

Health Informatics, 2006, "Sistem Informasi Manajemen Kesehatan", https://daniiswara.wordpress.com/2006/09/30/ health-informatics-sistem-informasimanajemen-kesehatan/.

Health Informatics, 2007, "Peluang Kerja Informatika Kesehatan", https://daniiswara.wordpress.com/2007/01/02/ health-informatics-peluang-kerja-informatikakesehatan/.

WHO, 2003. "Health Systems: principled integrated care". The world health report.

Yasnoff \& O'Carroll, 2000, "Public health informatics: improving and transforming public health in the information age", PubMed, US National Library of Medicine, National Institutes of Health. 